\title{
Foreign Bodies in Non-Life Threatening Locations: A Risk Analysis of Nose and Ears Foreign Bodies in European Children
}

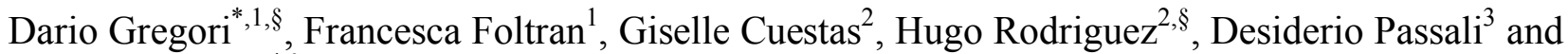 \\ Paola Berchialla ${ }^{4, \S}$ \\ ${ }^{1}$ Labs of Epidemiological Methods and Biostatistics, Department of Environmental Medicine and Public Health, \\ University of Padova, Italy \\ ${ }^{2}$ Endoscopy, Hospital de Pediatría Juan P. Garrahan, Garrahan, Buenos Aires, Argentina Buenos Aires, Argentina \\ ${ }^{3}$ Ear, Nose, and Throat Clinic, Policlinico Le Scotte, University of Siena, Italy \\ ${ }^{4}$ Department of Public Health and Microbiology, University of Torino, Italy
}

\begin{abstract}
Children with a foreign body (FB) in either the ear or nose commonly present to the hospital. We present a retrospective series of 1186 European cases of FB in ears or nose in children younger 14 years old, classified following the International Classification of Disease (ICD931 and ICD932). Data were collected through a case report form (CRF) during three years (2000-2002) according to four main characteristics (socio-demographic, ergonomic, related to the hospital's management and to the circumstance of the injury). Overall, 610 (53\%) sampled children were males. In 704 (71\%) of cases, FBs were inorganic and among themabout $36 \%$ were balls, marbles or beads. The study investigates FBs featuresand injuries circumstances that are associated to prolonged hospitalization and complications. The most dangerous FBs resulted in objects with rigid or semi-rigid consistency.
\end{abstract}

Keywords: Foreign body (FB), children, chocking, ears, nose.

\section{INTRODUCTION}

Foreign body (FB) insertion, ingestion, aspiration and inhalation is a common and serious problem among children in pediatric age. Unlike FB inhaled into the lower airway [1, 2] or ingested [3, 4], the presence of a foreign body in the ear or nose is not life-threatening, but it may result in significant morbidity [5-8].

Nasal foreign bodies (NFBs) are commonly observed in pediatric setting since boredom, curiosity, interests in exploring their bodies make children more prone to lodging foreign bodies (FB) in their nasal cavities [9].

In scientific literature a wide spectrum of foreign bodies has been documented and, most frequently, FBs are identified as toys, sweets, jewels, rocks, batteries, and magnets. The presence of a FB in the nose is not usually life threatening [10], however, it may result in long-term complications and it could be responsible even of fatal outcomes if the object is dislodged into the airway. Foreign body (FB) insertion in external auditory canal (EAC) is not an uncommon event in emergency medicine [7]. Several factors in fact may lead children to insert foreign bodies intentionally into the ears including curiosity, the wish to

*Address correspondence to this author at the Labs of Epidemiological Methods and Biostatistics, Department of Environmental Medicine and Public Health, University of Padova, Via Loredan 18, 35131 Padova, Italy; Tel: +39 049 8275384; Fax: +39 02 700445089;

E-mail: dario.gregori@unipd.it

${ }^{\S}$ Dario Gregori, Hugo rodriguez and Paola Berchialla are Guest Editors for the Issue. explore the orifices of the body, fun-making, irritation caused by otalgia and attraction to small, round-shaped objects $[11,12]$.

Although not life-threatening, the placement or presence of foreign bodies in the ear canal and their subsequent removal can be a source of significant morbidity. This is particularly true in children because of smaller anatomic dimensions and a variable level of cooperation [13].

Despite the frequency and potential morbidity circumstance there is very little literature based on large series of ear foreign bodies in children [11, 14].

Because of the risks associated with FB injuries, public health authorities must to devote great attention to this issue [10] and joint efforts, including the implementation of surveillance systems such as the Susy Safe Registry [15], have been made in several countries to better understand the injuries due to the FB insertion or inhalation and to identify shared prevention standards. Particularly, the integration of information coming from different clinical setting and crosscultural comparisons constitute a cornerstone of a monitoring activity aiming to identify risky $\mathrm{FB}$ and hazardous behavior, in order to implement normative and educational preventive strategies.

Unfortunately, while in scientific literature several papers describe clinical management of FBs [11, 16-19], data on follow up of patients after the foreign body extraction and thus on long terms outcomes are almost absent [20].

Based on a database of foreign body injuries, which occurred in European children aged up to 14 years in 2000- 
2003 , this paper will focus on the cases regarding ICD codes 931 (FB inside the ears) and 932 (FB inside the nose) to evaluate the causes of prolonged hospitalization and complication.

\section{MATERIALS \& METHODS}

The European Survey of Foreign Bodies Injuries (ESFBI) is a retrospective study, aimed at collecting a great case database concerning FB injuries in the upper airways (the accidents referred to the International Classification of Disease, ICD-codes), as regards to European children, aged 0-14 The discharge records from 19 European hospitals were reviewed. Data were gathered in the capitals' hospitals of 19 countries (Spain, United Kingdom, Germany, Switzerland, Austria, Italy, Belgium, Denmark, Finland, Sweden, Croatia, Slovenia, Greece, Slovakia, Czech Republic, Romania, Bulgaria, Turkey, Poland) and referred to the period starting from January, the 1st, 2000 and December, 31st, 2002 (whether available, also data from 2003 were considered).

Accidents, caused by the inhalation/ingestion/aspiration/ insertion of FBs, were collected using a standardized Case Report Form (CRF).

The CRF encompassed four main aspects of the FB injuries: the characteristics of the children (age, gender), the characteristics of the object (shape, consistency and dimension), circumstances of injury (presence of parents, activity) and hospitalization details (length of stay in hospital, complications).

The coordinating centre received the data and made the quality case control in collaboration with the European Federation of Oto-Rhino-Laryngological Societies (EUFOS) board. Dedicated doctors checked for all cases that presented not sufficient integrity and accuracy, such as those records with discrepancies among the birth date of the injured child and the accident date or missed completion of mandatory fields [21].

Two outcomes were identified: (i) complications and (ii) prolonged hospitalization, which was defined on the basis of the length of stay(LOS) of 3 days, at least.

Descriptive statistics of the study sample were done using percentages and absolute numbers. Prolonged hospitalization and complications were analyzed using odds ratios and related $95 \%$ confidence intervals. Analyses were performed using R version 2.8 and Hmisc and Design libraries [22].

\section{RESULTS}

A total of 1186 European children had a foreign body injuries with the FB located in ears or nose. Among them, 51\%

Table 1. Distribution of Complications and Hospitalization by Age, Gender, FB Removal Technique, Type of Admission and Adult Presence and FB Features

\begin{tabular}{|c|c|c|c|c|c|c|c|}
\hline & \multirow{3}{*}{$\mathbf{N}$} & \multicolumn{3}{|c|}{ Complications } & \multicolumn{3}{|c|}{ Prolonged hospitalization } \\
\hline & & No & Yes & OR $(95 \% C I)$ & <3 Days & $\geq 3$ Days & OR \\
\hline & & $\mathrm{N}=\mathbf{9 2 9}$ & $N=124$ & & $N=134$ & $\mathrm{~N}=7$ & \\
\hline Age class: $<1$ & 1178 & $1 \%(6)$ & $1 \%(1)$ & $0.82(0.10 ; 6.91)$ & $2 \%(2)$ & 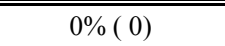 & NS \\
\hline $1-3$ & & $53 \%(487)$ & $29 \%(36)$ & $0.36(0.24 ; 0.55)$ & $41 \%(54)$ & $14 \%(1)$ & $0.49(0.06 ; 4.22)$ \\
\hline$>3$ & & $47 \%(429)$ & $70 \%(87)$ & Ref & $58 \% 76)$ & $86 \%(6)$ & Ref \\
\hline Gender : Male & 1164 & $53 \%(485)$ & $54 \%(66)$ & $1.03(0.71 ; 1.51)$ & $53 \%(69)$ & $14 \%(1)$ & $0.23(0.03 ; 2.00)$ \\
\hline FB removal technique: & 1061 & & & & & & \\
\hline Endoscopy & & $60 \%(555)$ & $33 \%(41)$ & Ref & $9 \%(12)$ & $29 \%(2)$ & Ref \\
\hline Operation & & $14 \%(127)$ & $9 \%(11)$ & $1.17(0.59 ; 2.34)$ & $76 \%(101)$ & $29 \%(2)$ & $0.12(0.02 ; 0.92)$ \\
\hline Other & & $26 \%(244)$ & $58 \%(72)$ & $3.9982 .65 ; 6.03)$ & $15 \%(20)$ & $43 \%(3)$ & $0.90(0.13 ; 6.18)$ \\
\hline Regime of hospitalization & 1186 & & & & & & \\
\hline Day Hospital & & $21 \%(105)$ & $29 \%(8)$ & $2.79(1.07 ; 7.24)$ & $75 \%(100)$ & $71 \%(5)$ & $0.50(0.05 ; 4.71)$ \\
\hline Emergency Service & & $74 \%(366)$ & $36 \%(10)$ & Ref & $7 \%(10)$ & $14 \%(1)$ & Ref \\
\hline Ordinary & & $5 \%(25)$ & $36 \%(10)$ & $14.64(5.57 ; 38.45)$ & $18 \%(24)$ & $14 \%(1)$ & $0.42(0.02 ; 7.34)$ \\
\hline Adult presence & 1186 & & & & & & \\
\hline Adult present & & $35 \%(287)$ & $39 \%(43)$ & $1.16(0.77 ; 1.75)$ & $40 \%(48)$ & $0 \%(0)$ & NS \\
\hline FB type: Inorganic & 1186 & $70 \%(653)$ & $65 \%(81)$ & $0.80(0.53 ; 1.19)$ & $78 \%(104)$ & $100 \%(7)$ & NS \\
\hline FB consistency : Conforming & 1034 & $18 \%(164)$ & $24 \%(29)$ & $1.42(0.88 ; 2.27)$ & $19 \%(24)$ & $0 \%(0)$ & NS \\
\hline Do not know & & $2 \%(21)$ & $1 \%(1)$ & $0.38(0.05 ; 2.89)$ & $0 \%(0)$ & $0 \%(0)$ & NS \\
\hline Rigid & & $57 \%(513)$ & $53 \%(64)$ & Ref & $61 \%(78)$ & $86 \%(6)$ & Ref \\
\hline Semi-rigid & & $23 \%(205)$ & $22 \%(27)$ & $1.06(0.65 ; 1.70)$ & $20 \%(25)$ & $14 \%(1)$ & $0.52(0.06 ; 4.53)$ \\
\hline FB shape : $2 \mathrm{D}$ & 993 & $7 \%(65)$ & $11 \%(11)$ & $2.24(1.09 ; 4.60)$ & $6 \%(8)$ & $0 \%(0)$ & NS \\
\hline 2D circle & & $7 \%(64)$ & $9 \%(9)$ & $1.86(0.86 ; 4.03)$ & $7 \%(9)$ & $14 \%(1)$ & NS \\
\hline $3 \mathrm{D}$ & & $18 \%(156)$ & $43 \%(45)$ & $3.82(2.39 ; 6.10)$ & $31 \%(38)$ & $43 \%$ ( 3 ) & $1.74(0.33 ; 9.04)$ \\
\hline other & & $10 \%(90)$ & $1 \%(1)$ & $0.15(0.02 ; 1.08)$ & $2 \%(3)$ & $0 \%(0)$ & NS \\
\hline Spherical & & $57 \%(503)$ & $37 \%(38)$ & Ref & $53 \%(66)$ & $43 \%(3)$ & Ref \\
\hline FB volume & 453 & 33.49113 .04267 .95 & 33.4965 .42152 .5 & $0.83(0.66 ; 1.03)$ & 6.018 .040 .0 & 30.8733 .4980 .37 & $3.91(0.99 ; 15.48)$ \\
\hline
\end{tabular}

Number after percents are absolute frequencies. For volume, I quartile/median/III quartile are reported. $\mathrm{N}$ is the number of non missing values. Odds ratio (OR) and $95 \%$ confidence interval were reported. 
were between 1-3 years old; $53 \%$ were males, according to previous studies [23, 24], which report a slightly higher incidence of FB injuries among males (Table 1).

Nineteen different objects were retrieved. Among them, $70 \%$ were inorganic, $55 \%$ had a spherical shape and $57 \%$ had a rigid consistency with volume ranging from 14 to 800 $\mathrm{mm}^{3}$.

Regarding the activity played by children immediately before the accident, playing is the most frequent (82\%); also in the $64 \%$ of cases, adults were absent.

Among injured children, $86 \%$ did not require hospitalization; in the $34 \%$ of cases the foreign body was removed using endoscopy in Emergency Service.

Overall, $11 \%$ of the children experienced complications. The most frequent complication was inflammation of external meatus and perforation of tympanic membrane and infection of nasal mucosa.

Surgery removal techniques showed anot significantly increased risk of complications than endoscopy $(\mathrm{OR}=1.17 ; 95 \%$ CI: 0.19-2.34); whereas 3D objects showed a significant increased risk of complicated injuries (with respect to spherical shaped foreign bodies) (O.R.=3.82, C.I. 2.39-6.10). Children older than three years old were at significantly greater risk of prolonged hospitalization (Table 1).

Inorganic foreign bodies were encountered more often in case of prolonged hospitalization (Table 1). Indeed they resulted associated with spherical and 3D shaped object and with rigid and semi-rigid consistency, which posed major risk of complicated injuries (Table $\mathbf{3}$ ).

A multivariable analysis for selecting predictors of prolonged hospitalization and complications was carried out. Shape and volume of the FB inserted its consistency along with organic/inorganic distinction, age and gender of the injured child, presence of complications (whether considering prolonged hospitalization as outcome) and the removal technique was considered as covariate for logistic regression model. After a backward selection procedure, age and shape of FBs were the only significant variable for predicting prolonged hospitalization and presence of complications (Table 3). In Fig. (1), probability of experiencing complications and having prolonged hospitalization is showed as function of age in the case of injuries due to 3D foreign bodies.

Table 2. Foreign Bodies Features According to Inorganic/Organic Distinction

\begin{tabular}{|c|c|c|c|c|}
\hline & \multirow{2}{*}{$\mathbf{N}$} & Inorganic & Organic & \multirow{2}{*}{$\begin{array}{c}\text { Test } \\
\text { Statistic }\end{array}$} \\
\hline & & $N=825$ & $N=346$ & \\
\hline Shape : 2D & 993 & $5 \%(36)$ & $15 \%(41)$ & $\mathrm{P}<0.001$ \\
\hline 2D circle & & $9 \%(62)$ & $5 \%(14)$ & \\
\hline $3 \mathrm{D}$ & & $20 \%(143)$ & $21 \%(59)$ & \\
\hline other & & $6 \%(43)$ & $15 \%(43)$ & \\
\hline Spherical & & $60 \%(420)$ & $44 \%(121)$ & \\
\hline Consistency: Conforming & 1034 & $11 \%(79)$ & $39 \%(114)$ & $\mathrm{P}<0.001$ \\
\hline Do not know & & $0 \%(0)$ & $5 \%(16)$ & \\
\hline Rigid & & $70 \%(513)$ & $23 \%(69)$ & \\
\hline Semi-rigid & & $19 \%(137)$ & $32 \%(95)$ & \\
\hline Volume & 453 & 33.49113 .04267 .95 & 54.082 .0189 & $\mathrm{P}=0.77$ \\
\hline
\end{tabular}

Test used: Chi-square test for shape and consistency and Wilcoxon test for volume.

Table 3. Multivariable Model for the Predictors of Complications and Prolonged Hospitalization

\begin{tabular}{|c|c|c|c|c|c|c|}
\hline \multirow{3}{*}{$\begin{array}{l}\text { Factor } \\
\text { Age }\end{array}$} & \multicolumn{3}{|c|}{ Complications } & \multicolumn{3}{|c|}{ Prolonger Hospitalization } \\
\hline & \multirow{2}{*}{$\begin{array}{c}\text { OR } \\
3.19\end{array}$} & \multicolumn{2}{|c|}{$95 \%$ CI } & \multirow{2}{*}{$\begin{array}{c}\text { OR } \\
1.76\end{array}$} & \multicolumn{2}{|c|}{$95 \%$ CI } \\
\hline & & 1.67 & 6.09 & & 0.14 & 22.81 \\
\hline \multicolumn{7}{|l|}{ Shape } \\
\hline 2D:Spherical & 2.34 & 1.12 & 4.92 & 0.01 & 0 & $1.07 \mathrm{E}+22$ \\
\hline 2D circle:Spherical & 1.83 & 0.83 & 4.01 & 3.58 & 0.3 & 43.52 \\
\hline 3D:Spherical & 4.17 & 2.57 & 6.75 & 1.49 & 0.27 & 8.25 \\
\hline other:Spherical & 0.15 & 0.02 & 1.13 & 0 & 0 & $4.31 \mathrm{E}+40$ \\
\hline \multicolumn{7}{|l|}{ Consistency } \\
\hline Conforming: Rigid & 1.34 & 0.74 & 2.43 & - & - & - \\
\hline Semirigid:Rigid & 1.01 & 0.59 & 1.71 & 0.50 & 0.05 & 5.32 \\
\hline
\end{tabular}



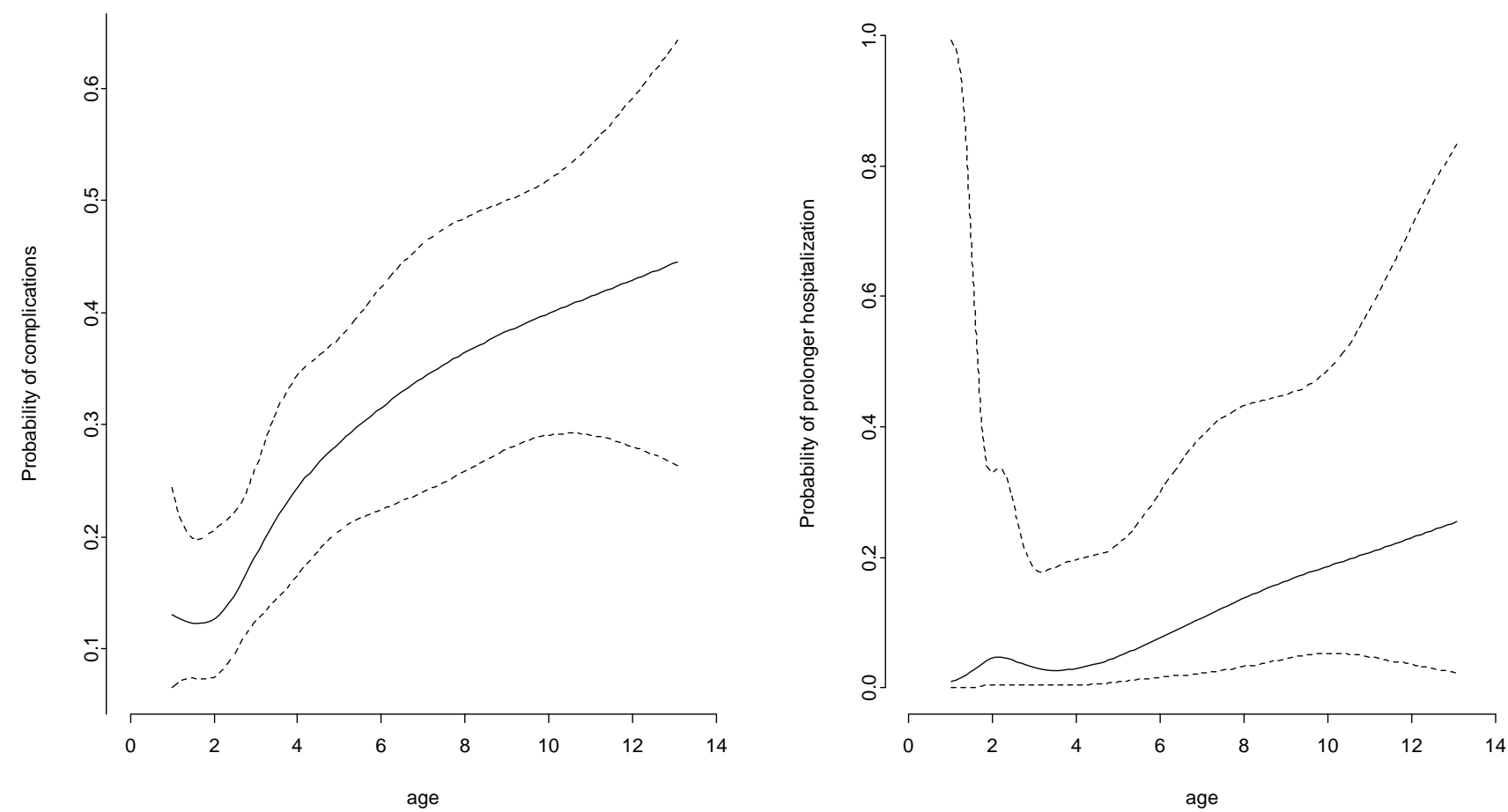

Fig. (1). Probability of experiencing complication (left) and prolonged hospitalization (right) as function of age for injuries due to 3D rigid foreign bodies.

\section{DISCUSSION}

Inhalation and aspiration of foreign bodies maintain their connotation of high prevalence cause of injury in children. Unfortunately, FB injuries are a neglected epidemic and there's a lack of sensibility in terms of recognition and acknowledgement of the FB injury risk; the constant evolvement of the FB typology, as new products reach the market, makes the information on product specific hazard and symptoms scattered; moreover, in most of the cases the diagnosis is difficult since symptoms are absolutely a specific [25].

Particularly, foreign bodies in the nose and in the ears produce local inflammation which may result in a pressure necrosis and damage the surrounding structure [26]. Nasal symptoms are mainly caused by inflammation, mucosal damage and extension into adjacent structures and could include sneezing, epistaxis, nasal obstruction, nasal discharge, pain, and eventually rhinosinusitis. Similarly, a FB in the ear may result in significant morbidity because of the small anatomic size and delicate skin of EAC and the thinness of the tympanic membrane [27].

In our case series the most frequent symptoms was bleeding and infections of external ear and nasal mucosa constituted well documented complications.

As observed elsewhere, the first determinants of a damage requiring hospitalization are the age of the child and the shape of the object; on the opposite, differently from the most common findings, food and organic FB appear to be less dangerous than inorganic $\mathrm{FB}$, whose relative inert nature is believed to imply a mild tissue inflammation and a relatively quick response of the patient upon removal [28].
However, inorganic FB more frequently than food have shape and consistency identified as risky in our analysis

Adult presence is not sufficient to prevent hazardous situations: in our experiences almost $90 \%$ of injuries happen under adult supervision stressing the evidence that preventive strategies imposing a regulation of industrial production, even if fundamental, are not sufficient and need to be integrated with other preventive intervention, addressed to improve parents consciousness and attention toward a proper surveillance of children.

Consciousness toward foreign body injuries in children is needed also in order to address the problem from the public health perspective. In fact, the economic impact of hospitalization and complication of FB injuries on public health costs [29] confirms that FB injuries need a public health approach to be tackled effectively.

\section{THE ESFBI STUDY GROUP}

\section{Coordinating Center}

Prof. Roberto Corradetti, University of Torino, Italy

Prof. Dario Gregori, University of Padova, Italy

Prof. Desiderio Passali, University of Siena, Italy

Dr Silvia Snidero, University of Torino, Italy

\section{Austria}

Prof. Albegger Klaus, Head of the ENT-Department, Salzburg, Austria

Dr. Huttegger Isidor, Universitätsklinik für Kinder- und Jugendheilkunde, Salzburg, Austria 
Dr. Schulz Gernot, Universitätsklinik für Kinder- und Jugendheilkunde, Salzburg, Austria

Dr. Bauer Jan, Universitätsklinik für Kinder- und Jugendheilkunde, Salzburg, Austria

\section{Belgium}

Prof. Bertrand Bernard, Cliniques Universitaires UCL de Mont-Godinne, ENT Dept., Yvoir, Belgium

\section{Bulgaria}

Prof. Karchev Todor, University Hospital "Tzaritza Joanna", Sofia, Bulgaria

Prof. Tzolov Tzolo, University Hospital "Tzaritza Joanna", Sofia, Bulgaria

\section{Croatia}

Prof. Mladina Ranko, ORL Department, University Hospital Salata-KBC, Zagreb, Croatia

Dr. Kovac Lana, ORL Department, University Hospital Salata-KBC, Zagreb, Croatia

\section{CzechRepublic}

Dr. Slapak Ivo, Pediatric ENT Department of Childrens University Hospital, Brno, Czech Republic

\section{Denmark}

Prof. Tos Mirko, Gentofte University Hospital of Copenhagen, Hellerup, Denmark

Prof. PerCaye-Thomasen, Gentofte University Hospital of Copenhagen, Hellerup, Denmark

\section{Finland}

Dr. Pitkäranta Anne, Helsinki University Central Hospital, Helsinki, Finland

\section{Germany}

Prof. Jahnke Volker, Charitè Campus Virchow Klinikum, Berlin, Germany

Dr. Göktas Önder, Charitè Campus Virchow - Klinikum, Berlin, Germany

\section{Greece}

Prof. Nikola Simasko, Democritus University of Thrace, Ent Department, Alexandrupolis, Greece

Dr. Chroni Matilda, Agia Sophia Children Hospital, Ent Department, Athens, Greece

Dr. Dr IoannisChristopoulos, Agia Sophia Children Hospital, Ent Department, Athens, Greece

\section{Italy}

Prof. Desiderio Passàli, Dept. of Otorhinolaryngolgy, University of Siena, Italy

Prof. Luisa Bellussi, Dept. of Otorhinolaryngolgy, University of Siena, Italy

Dr. Giulio Cesare Passàli, Dept. of Otorhinolaryngolgy, University of Siena, Italy
Dr. Francesco Passàli, Dept. of Otorhinolaryngolgy, University of Siena, Italy

Dr. Valerio Damiani, Dept. of Otorhinolaryngolgy, University of Siena, Italy

\section{Poland}

Prof. ChmielikMieczysław, Department of Pediatric Otorhinolaryngology,

The Medical University of Warsaw, Poland

\section{Romania}

Prof. Sarafoleanu Dorin, Clinica ORL, Sfanta Maria Hospital, Bucharest, Romania

Dr. Sarafoleanu Codrut, Clinica ORL, "Sfanta Maria Hospital", Bucharest, Romania

Dr. Dan Cristian Gheorghe, Clinica ORL, "Spitalul de Copii Marie Curie", Bucharest, Romania

\section{Slovakia}

Prof. Jakubíková Janka, Pediatric Otolaryngology Department of Medical Faculty of Comenius University, Bratislava, Slovakia

\section{Slovenia}

Prof. Žargi Miha, Department of Otorhinolaryngolgy and Cervicofacial Surgery, University Medical Centre, Ljubljana, Slovenia

Dr. Grošelj Aleš, Department of Otorhinolaryngolgy and Cervicofacial Surgery, University Medical Centre, Ljubljana, Slovenia

Dr. Matos Aleš, Department of Otorhinolaryngolgy and Cervicofacial Surgery, University Medical Centre, Ljubljana, Slovenia

\section{Spain}

Prof. Rubio Lorenzo, Jefe de la Unidad ORL - Hospital Ruber International, Madrid Spain

Dr. Cervera Javier, Hospital Niño Jesus, Madrid, Spain

\section{Sweden}

Prof. Stierna Pontus, Karolinska University Hospital Huttinge, Stockholm, Sweden

\section{Switzerland}

Prof. Pasche Philippe, Service ORL, Centre Hospitalier Universitaire Vaudois, Lausanne, Switzerland

Dr. Cherif Ahmed, Service ORL, Centre Hospitalier Universitaire Vaudois, Lausanne, Switzerland

\section{Turkey}

Prof. Önerci T. Metin, Hacettepe University, Dept. of Otorhinolaryngology, Ankara, Turkey

Dr. Çiftçi Arbay Özden, Hacettepe University, Faculty of Medicine, Dept of Pediatric Surgery, Ankara, Turkey

Dr. Doğan Riza, Hacettepe University, Faculty of Medicine, Dept of Cardiovascular Surgery, Ankara, Turkey 


\section{United Kingdom}

Prof. Graham John, Royal Free Hospital, London, UK

Dr. Rea Peter, Royal Free Hospital, London, UK

Dr. Obholtzer Rupert, Royal Free Hospital, London, UK

\section{ACKNOWLEDGEMENT}

None declared.

\section{CONFLICT OF INTEREST}

None declared.

\section{REFERENCES}

[1] Kaushal P, Brown DJ, Lander L, Brietzke S, Shah RK. Aspirated foreign bodies in pediatric patients, 1968-2010: a comparison between the United States and other countries. Int J Pediatr Otorhinolaryngol 2011;75(10):1322-6.

[2] Lando T, Cahill AM, Elden L. Distal airway foreign bodies: Importance of a stepwise approach, knowledge of equipment and utilization of other services' expertise. Int J Pediatr Otorhinolaryngol 2011;75(7):968-72.

[3] Chinski A, Foltran F, Gregori D, Ballali S, Passali D, Bellussi L. Foreign Bodies in the Oesophagus: The experience of the Buenos Aires pediatric ORL clinic. Int J Pediatr 2010; 2010: pii. 490691.

[4] Gregori D, Scarinzi C, Morra B, et al. Ingested foreign bodies causing complications and requiring hospitalization in European children: results from the ESFBI study. Pediatr Int 2010 ;52(1):2632.

[5] Chinski A, Foltran F, Gregori D, et al. Foreign bodies in the ears in children: the experience of the Buenos Aires pediatric ORL clinic. Turk J Pediatr 2011;53(4):425-9.

[6] Chinski A, Foltran F, Gregori D, Passali D, Bellussi L. Nasal foreign bodies: the experience of the Buenos Aires pediatric otolaryngology clinic. Pediatr Int 2011;53(1):90-3.

[7] Gregori D, Morra B, Berchialla P, et al. Foreign bodies in the ears causing complications and requiring hospitalization in children 0 14 age: results from the ESFBI study. Auris Nasus Larynx 2009 ;36(1):7-14.

[8] Tong MC, Ying SY, van Hasselt CA. Nasal foreign bodies in children. Int J Pediatr Otorhinolaryngol 1996 ;35(3):207-11.

[9] Das SK. Aetiological evaluation of foreign bodies in the ear and nose. J Laryngol Otol 1984; 98(10):989-91.

[10] Gregori D, Salerni L, Scarinzi C, et al. Foreign bodies in the nose causing complications and requiring hospitalization in children 014 age: results from the European survey of foreign bodies injuries study. Rhinology $2008 ; 46(1): 28-33$.

[11] Balbani AP, Sanchez TG, Butugan O, et al. Ear and nose foreign body removal in children. Int J Pediatr Otorhinolaryngol 1998; 46(1-2):37-42.
[12] Bressler K, Shelton C. Ear foreign-body removal: a review of 98 consecutive cases. Laryngoscope $1993 ; 103: 367-70$.

[13] Ansley JF, Cunningham MJ. Treatment of aural foreign bodies in children. Pediatrics $1998 ; 101: 638-41$.

[14] Schulze SL, Kerschner J, Beste D. Pediatric external auditory canal foreign bodies: a review of 698 cases. Otolaryngol Head Neck Surg $2002 ; 127(1): 73-8$.

[15] Gregori D. The Susy Safe Project. A web-based registry of foreign bodies injuries in children. Int J Pediatr Otorhinolaryngol 2006 ;70(9):1663-4.

[16] Backlin SA. Positive-pressure technique for nasal foreign body removal in children. Ann Emerg Med 1995;25(4):554-5.

[17] Navitsky RC, Beamsley A, McLaughlin S. Nasal positive-pressure technique for nasal foreign body removal in children. Am J Emerg Med $2002 ; 20(2): 103-4$.

[18] Mackle T, Conlon B. Foreign bodies of the nose and ears in children. Should these be managed in the accident and emergency setting? Int J Pediatr Otorhinolaryngol $2006 ; 70(3): 425-8$.

[19] Dubois M, Francois M, Hamrioui R. [Foreign bodies in the ear; report of 40 cases]. Arch Pediatr 1998 ;5(9):970-3.

[20] Foltran F, Gregori D, Passali D. Foreign bodies inhalation as a research field: What can we learn from a bibliometric perspective over 30 years of literature? Int J Pediatr Otorhinolaryngol 2010; [Epub ahead of print].

[21] Berchialla P, Stancu A, Scarinzi C, Snidero S, Corradetti R, Gregori D. Web-based tool for injury risk assessment of foreign body injuries in children. J Biomed Inform 2008;41(4):544-56.

[22] R Development Core Team. R: A language and environment for statistical computing. 2008.

[23] Tan HK, Brown K, McGill T, Kenna MA, Lund DP, Healy GB Airway foreign bodies (FB): a 10-year review. Int J Pediatr Otorhinolaryngol. 2000 1;56(2):91-9.

[24] Endican S, Garap JP, Dubey SP. Ear, nose and throat foreign bodies in Melanesian children: an analysis of 1037 cases. Int J Pediatr Otorhinolaryngol 2006; 70(9):1539-45.

[25] Gregori D, Foltran F, Passali D. Foreign body injuries in children: need for a step forward against an old yet neglected epidemic. Paediatr Perinat Epidemiol $2011 ; 25(2): 98-9$.

[26] Kalan A, Tariq M. Foreign bodies in the nasal cavities: a comprehensive review of the aetiology, diagnostic pointers, and therapeutic measures. Postgrad Med J 2000;76(898):484-7.

[27] Olajide TG, Ologe FE, Arigbede OO. Management of foreign bodies in the ear: a retrospective review of 123 cases in Nigeria Ear Nose Throat J $2011 ; 90(11): 16-9$.

[28] Foltran F, Gregori D, Passali D, et al. Toys in the upper aerodigestive tract: evidence on their risk as emerging from the ESFBI study. Auris Nasus Larynx 2011; 38(5): 612-7.

[29] Gregori D, Scarinzi C, Berchialla P, et al. The cost of foreign body injuries in the upper aero-digestive tract: need for a change from a clinical to a public health perspective? Int $\mathrm{J}$ Pediatr Otorhinolaryngol 2007; 71(9): 1391-8. 